\title{
Altruism in insect societies and beyond: voluntary or enforced?
}

\author{
Francis L.W. Ratnieks ${ }^{1}$ and Tom Wenseleers ${ }^{2}$ \\ ${ }^{1}$ Laboratory of Apiculture and Social Insects, Department of Animal and Plant Sciences, University of Sheffield, Sheffield, \\ S10 2TN, UK \\ ${ }^{2}$ Laboratory of Entomology, Zoological Institute, Catholic University of Leuven, 3000 Leuven, Belgium
}

\begin{abstract}
The altruism of insect workers has puzzled researchers for decades. Inclusive fitness theory suggests that high relatedness has been key in promoting such altruism. Recent theory, however, indicates that the intermediate levels of relatedness found within insect societies are too low to directly cause the extreme altruism observed in many species. Instead, recent results show that workers are frequently coerced into acting altruistically. Hence, the altruism seen in many modern-day insect societies is not voluntary but enforced. Here, we also consider the role of coercion in promoting altruism and cooperation in other social systems, such as vertebrate and human societies, and interspecific mutualisms.
\end{abstract}

\section{Altruism in insect societies}

Altruism in nature (see Glossary) is nowhere seen as plainly as in insect societies, in which the workers sacrifice most or all of their direct reproduction to help rear the queen's offspring [1]. How did natural selection, which normally favours increased reproduction, cause individuals to help others at a cost to their own reproduction [2]? A key breakthrough was Hamilton's theory of inclusive fitness [3,4], which shows that altruism can be favoured, provided that altruist and beneficiary are genetically related [2-4].

At first glance, insect societies seem to fit this scenario because most comprise highly related family groups in which workers help to rear their mother queen's offspring. However, when Hamilton's theory is applied, it is normally assumed that whether an individual is altruistic is under the control of the individual itself, that is altruism is voluntary and not socially enforced. But is this true for social insect altruism? As we argue here, in many cases it is not. Over the past few decades, several important coercive behaviours have been discovered in insect societies (Figure 1) [5], ranging from the killing of worker-laid eggs [6] to preventing larvae from developing into queens via food control [1]. In inclusive fitness terms, such coercion promotes altruism because it reduces the benefit of attempting to reproduce directly relative to the benefit of rearing non-descendant kin $[7,8]$. That is, by hindering direct reproduction, social pressure causes individuals to acquiesce and thereby become more altruistic. The basic idea is not new: in 1974, Richard Alexander proposed that altruism in insect societies could have arisen as a result of

Corresponding author: Ratnieks, F.L.W. (F.Ratnieks@Sheffield.ac.uk). parents forcing their offspring to act as helpers [9] (see also Refs $[10,11])$. Similarly, Frank has argued for the importance of social control mechanisms in promoting cooperation in a wide range of systems [12]. Nevertheless, it is only recently that theoretical models have been developed that specifically determine the extent to which altruism in insect societies is enforced $[7,13]$ and that enough empirical evidence has accumulated to test the predictions of these models [14]. Here we summarize this work. We emphasize worker altruism in modern-day insect societies but also consider whether coercion could have been important in the origin of eusociality. We finish with a discussion of the broader role of coercion in promoting cooperation and altruism in other social systems, such as vertebrate

\section{Glossary}

Acquiescence: a situation whereby coercion favours individuals to comply with the social norms of the group, even if this is not their first choice [7].

Altruism: an action that, on average, decreases the lifetime direct fitness of an actor and benefits one or more recipients [4].

Coercion: social pressure in the form of the punishment or policing of group members, usually to prevent them from acting selfishly and thereby harming the group or colony as a whole; the words enforcement and sanction have similar meanings [5].

Enforced altruism: altruism, or the level of altruism, favoured by natural selection acting on individuals in social groups with coercion [14].

Eusociality: social groups in which some individuals specialise in work or helping to enhance the direct reproduction of others.

Hamilton's rule: the inequality $r B>C$ arising from W.D. Hamilton's inclusive fitness theory [4] that predicts when a social action, such as altruism, is favoured; $r, C$ and $B$ are relatedness and the costs and benefits of the action to the actor and recipient, respectively.

Inclusive fitness: the total fitness of an actor resulting from its own reproduction (direct fitness) and the effect it has on the reproduction of others, weighted by relatedness (indirect fitness) [4].

Mutualism: a cooperative interaction that increases the lifetime direct fitness of both the actor and one or more recipients - partners generally belong to different species [4,54]; as for altruism, mutualism can be either voluntary or enforced (i.e. it can occur with or without coercion).

Parental manipulation: the theory [9] that parents can manipulate their offspring to help; extensions of the theory also consider manipulation by siblings.

Policing: behaviour that targets defectors but need not directly prevent individuals from acting selfishly in the future [12,32]; in the social insect literature the terms 'queen policing' [1] and 'worker policing' [32] mean the processes whereby the queen or the workers inhibit reproduction by workers via aggression or the eating of worker-laid eggs.

Punishment: a social act that deters recipients from acting selfishly in the future [50]; usually has delayed direct or inclusive fitness benefits to the punishing individual.

Relatedness: the correlation in genotype or behaviour of interacting individuals [4]; a correlation in behaviour can also arise from nongenetic causes, for example cultural resemblance ('cultural relatedness') [65].

Voluntary altruism: altruism, or the level of altruism, favoured by natural selection acting on individuals in social groups in the absence of coercion [14]. 

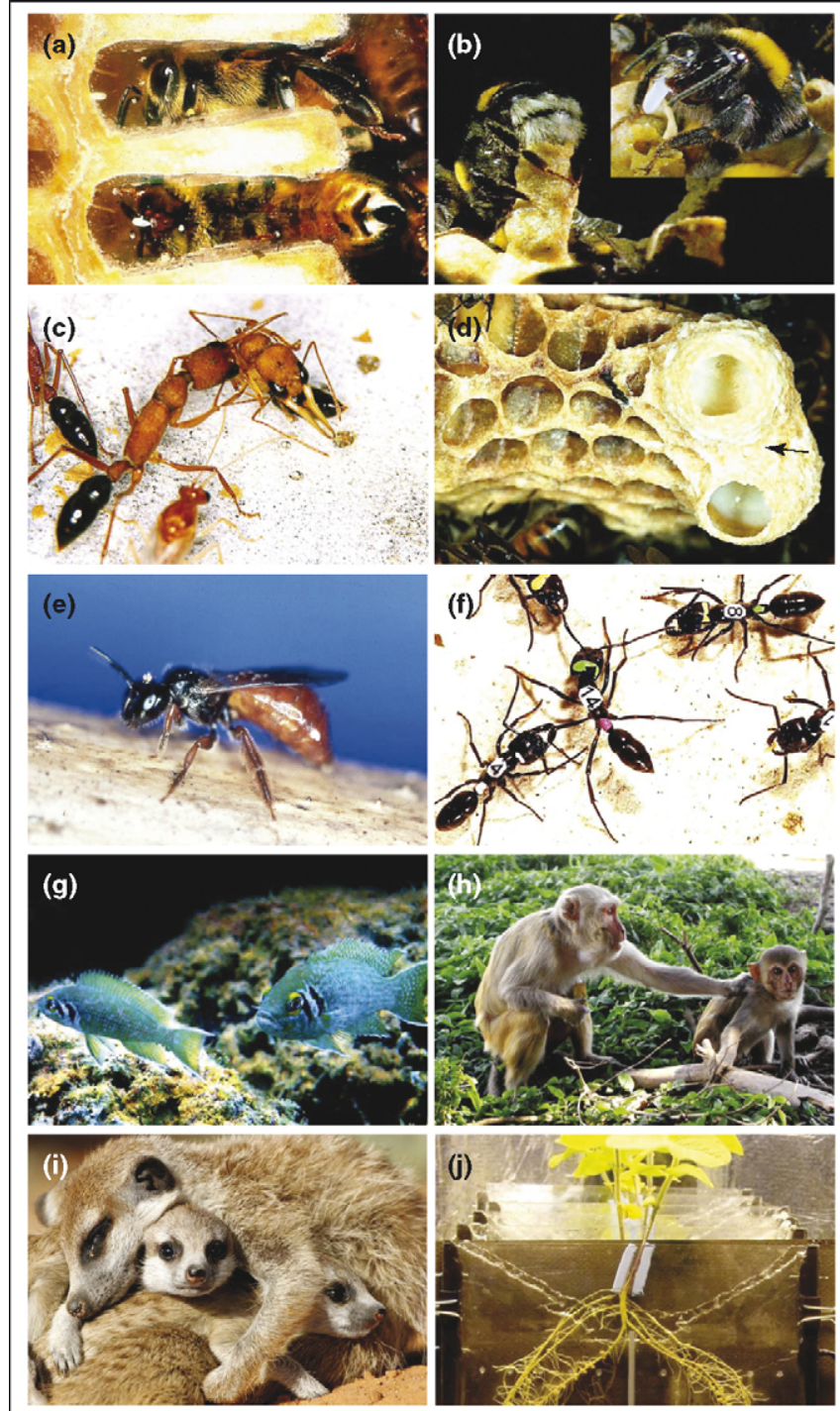

$\overline{\text { TRENDS in Ecology \& Evolution }}$

Figure 1. Enforced cooperation in insect and vertebrate societies and interspecific mutualisms. (a) Worker policing prevents workers from reproducing in the honeybee Apis mellifera [6]; (b) queen policing (inset) prevents most workers from reproducing successfully in the bumblebee Bombus terrestris [18]; (c) a worker with active ovaries is aggressed in the queenless ant Harpegnathos saltato [19]; (d) in the honeybee, differential feeding forces most larvae to develop as workers; only larvae reared in royal cells (arrow) can develop as queens [1,7]; (e) subordinate workers from the allodapine bee Exoneura bicolor are evicted from the nest when they have been in contact with a foreign male [39]; (f) a worker that attempted to overthrow the breeder female is punished in the queenless an Dinoponera quadriceps [40]; (g) in the cooperatively breeding cichlid Neolamprologus pulcher, subordinates that do not help look after the eggs and fry are evicted [57]; (h) rhesus monkeys (Macaca mulatta) who do not share food are punished [58]; (i) in meerkats (Suricata suricata) dominant females prevent successful breeding by subordinates [62]; (j) soybean plants (Glycine max) sanction root nodule bacteria that do not fix nitrogen, as shown by this split root experiment [55]. Reproduced, with permission, from F.L.W. Ratnieks (a,d), the BBC Natural History Unit (Life in the Undergrowth series) (b), J. Liebig (c), M. Schwarz (e), T. Monnin (f), J. Desjardins (g), M. Hauser (h), A. Young (i) and B. Rousseau (j).

societies, including vertebrate and human societies, and interspecific mutualisms.

\section{Family levels of relatedness are insufficient for complete voluntary altruism}

Hamilton's rule shows that higher relatedness favours greater altruism [3,4]. In hymenopteran insect societies headed by a single, once-mated queen, sisters are highly related, by 0.75 [4]. However, are the observed levels of relatedness sufficient to explain the extreme worker altruism observed in many insect societies? For example, in the honeybee Apis mellifera, queens mate with about ten males, and workers are related by only 0.3 [15]. How can this low level of relatedness result in societies in which fewer than one in 1000 workers attempts to lay eggs [16] or one in 10000 female larvae develops into a queen [17]? Recent theory suggests that, in the absence of coercion, it cannot $[7,13]$.

The reason becomes clear when we consider egg laying by workers [7,13]. In the social Hymenoptera, workers can lay haploid, male-destined eggs (Figure 2). They are selected to do so because they are more related to their own sons than to sons of either their mother queen or sister workers [2]. Nevertheless, not all workers are selected to reproduce. If all workers laid eggs, thereby leaving none to work, the colony would die and the inclusive fitness of every individual, including the egg layers, would be zero [17]. The equilibrium proportion of workers that should reproduce, in the absence of coercion, can be determined from Hamilton's rule [13] (Box 1) and is 14\% for species such as stingless bees or bumblebees, in which queens mate with a single male [15], and $54 \%$ for the honeybee. Importantly, these figures suggest that the intermediate relatedness levels found in insect societies cannot cause the extreme altruism found in the honeybee and many other species, in which very few workers reproduce. Theory, however, also shows that these high levels of worker altruism can occur if the potential altruists are coerced, that is if altruism is enforced. In the honeybee, workers selectively kill or police eggs laid by other workers [6]. Theory shows that such policing can reduce the incentive for workers to lay eggs to such an extent that few, or even none, should even attempt to do so [7].

\section{Evidence for enforced altruism: egg-laying by workers}

Although worker policing was first discovered in the honeybee [6], it has since been found in several other ant, bee and wasp species [5,18]. The killing of worker-laid eggs by the queen (queen policing) is also widespread and is particularly common in species with small colonies [5,18]. If policing does coerce altruism by reducing the opportunity for workers to reproduce, we predict that fewer workers should lay eggs in species with more effective egg policing $[7,13]$. Recently, a comparative study of ten species found strong support for this prediction: species in which worker-laid eggs had a greater chance of being killed had smaller proportions of egg-laying workers [14] (Figure 3).

The deterrent effect of coercion has also been shown by comparing worker reproduction in colonies with and without a queen [14] (Figure 3). In queenless colonies, policing is absent, and a last batch of worker-derived males is reared before the colony dies out. In queenless honeybee colonies $\sim 40 \%$ of the workers lay eggs [14]. This proportion is close to the inclusive fitness theory prediction based on voluntary altruism alone (54\%, Box 1) and greater than the $0.01-0.1 \%$ that reproduce in colonies with a queen [16].

Queenless colonies give an idea of what insect societies would be like if enforcement were absent and altruism 

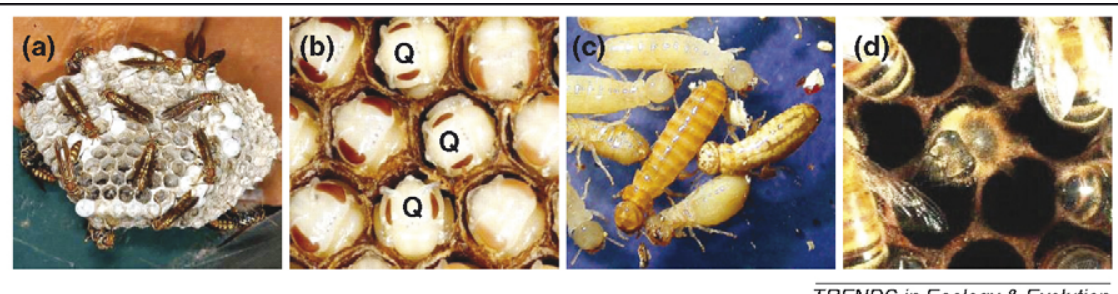

TRENDS in Ecology \& Evolution

Figure 2. Opportunities for direct reproduction in insect societies. Workers or developing individuals can behave non-altruistically by attempting to reproduce directly rather than by helping to rear the queen's offspring. (a) In this polistine wasp, Polistes versicolor, adult females could either mate and replace the queen or leave the nest and found a nest independently; (b) in this stingless bee, Melipona asilvae, queens and workers are reared in the same cells, giving female larvae the potential to develop into either queens $(\mathrm{Q})$ or workers, as shown in this comb in which the cells have been opened experimentally; (c) in the lower termite, Cryptotermes domesticus, all individuals can moult into replacement reproductives (centre) when the royal pair is removed; (d) in the honeybee Apis mellifera, workers can lay unfertilized, maledestined eggs. Reproduced, with permission, from T. Wenseleers (a, b), J. Korb (c) and B. Oldroyd (d).

were purely voluntary. Work continues but not as efficiently, because much potential labour is wasted in reproductive competition. This is not beneficial to the colony because more eggs are laid than can be reared, and egg-laying individuals also waste time in aggressive

\section{Box 1. Why coercion can be more powerful than kinship in promoting altruism}

To illustrate why family levels of relatedness are insufficient to cause complete voluntary altruism, consider egg-laying by social insect workers. If worker reproduction is not policed and if egg-laying workers carry out no work in the colony, the inclusive fitness benefit for a non-egg-laying worker to switch to laying eggs can be calculated from Hamilton's rule as $(1 / e)\left(r_{s}-r_{m}\right)>(1 / w)\left(r_{f}+r_{m}\right)$ [13], where $e$ and $w$ are the number of egg-laying and non-egg-laying workers, respectively, already present and $r_{s}, r_{f}$ and $r_{m}$ are the (life-for-life) relatedness coefficients [2] of workers to sons, sisters and males reared in the colony, respectively. The left-hand side of this inequality is the inclusive fitness benefit of laying eggs that with probability $1 / e$ will cause average males in the colony (value $r_{m}$ ) to be replaced by sons (value $r_{s}$ ). The right-hand side is the inclusive fitness cost caused by making the colony an amount $1 / w$ less productive, so that fewer queens (value $r_{f}$ ) and males (value $r_{m}$ ) will be reared. This equation gives an equilibrium proportion of egg-laying workers of $e /(e+w)=\left(r_{s}-r_{m}\right) /\left(r_{f}+r_{s}\right)$.

When colonies are large, the algebra can be simplified further because unpoliced worker reproduction will result in most of the males reared in the population being workers' sons. This increases male reproductive value [2] so that the relatedness of workers to nephews and sisters is equal $\left(r_{m}=r_{f}\right)$ and the relatedness to sons becomes $1\left(r_{s}=1\right)$. This gives equilibrium proportions of egg-laying workers of $14 \%, 33 \%$, and $54 \%$ [13] for relatednesses among workers of $0.75,0.5$, and 0.3 , corresponding to queen mating frequencies of 1,2 and 10 , respectively.

These results show that, in the absence of policing, a significant proportion of the workers are selected to lay eggs. Effective policing, however, can reduce the benefit of worker reproduction to zero, because the costs of worker reproduction (i.e. not working) remain the same, whereas the benefits are much reduced, because fewer workers' sons are reared $[7,13]$. Hence, situations in which all or almost all of the workers refrain from laying eggs cannot be caused by family relatedness alone, but can be caused by effective policing $[7,13]$.

A similar analysis of caste fate conflict for swarm-founding species [17] shows that individual females are selected to develop into queens (as opposed to workers) with a probability of $\left(1-r_{f}\right) /$ $\left(1+r_{m}\right)$. Hence, between $20 \%$ and $56 \%$ of all females should develop as queens depending on whether mother queens mate with a single male (as in stingless bees, giving $r_{f}=0.75$ ) or with ten males (as in the honeybee, giving $r_{f}=0.3$ ), assuming that all males are the queen's sons so that $r_{m}=0.25$. Again, these results show that unless female larvae are coerced to develop into workers, such as by food control, an excess would develop into queens [7]. interactions with each other. The absence of coercion also means that queenless colonies provide an opportunity for investigating the inclusive fitness prediction that higher relatedness should lead to greater voluntary altruism [4]. This prediction, which arises directly from Hamilton's rule, is strongly supported: species with higher relatedness have significantly lower proportions of egg-laying workers [14] (Figure 3).

Because egg policing is directed against worker-laid eggs, rather than against the egg-laying workers themselves, coercion is indirect. In this situation, over many generations, natural selection can adjust the proportion of laying workers to the prevailing levels of kinship and policing. However, coercion can also be direct. In some ponerine ants, laying workers are treated aggressively, and this can cause their ovaries to regress [19].

\section{Evidence for enforced altruism: female caste fate}

Another fundamental example of altruism in insect societies occurs when female larvae develop as workers instead of queens. In general, there is a strong incentive for female larvae to develop into queens because each female is more related to her own offspring than she is to her sisters' offspring [20]. Yet, in many species few female larvae develop as queens. For example, only $0.01 \%$ of honeybees develop into queens [17], enough to allow the colony to produce a few swarms a year, each comprising a queen accompanied by thousands of workers. Theory shows that this low level of queen production cannot be based solely on voluntary altruism. In fact, models show that, if honeybee larvae were free to choose their own caste fate, approximately half should develop as queens [17] (Box 1). Such vast queen overproduction is prevented by the adult workers that control larval feeding. Queens are larger and are reared in special queen cells on royal jelly, whereas larvae in the smaller worker cells are given insufficient food to become queens and so have to become workers.

Comparing queen production in honeybees with that of their close relatives the stingless bees (Meliponinae) supports these ideas [20-22]. As in honeybees, stingless bees establish new colonies by swarming. In most genera, queens are larger than workers, and only a few queens are reared [5,17]. However, in the genus Melipona, queens and workers are the same size and are reared in identical, closed cells (Figure 2). As a result, workers cannot coerce female larvae and up to $20 \%$ develop into queens [21,22], 


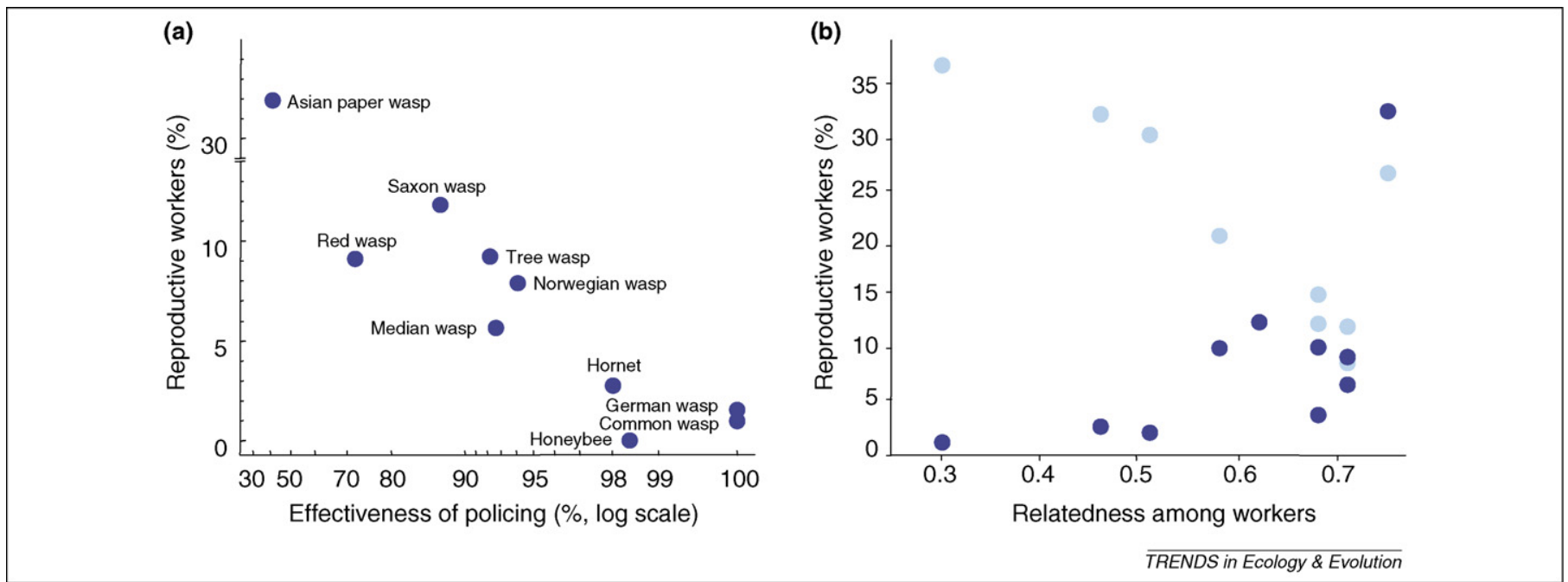

Figure 3. Evidence for enforced altruism in insect societies. (a) A comparative analysis of nine wasp species and the honeybee Apis mellifera shows that significantly fewer workers attempt to reproduce when the eggs they lay are more effectively killed or 'policed' by nestmates. (b) Paradoxically, in colonies with a queen, more workers reproduce in species in which workers are more related to each other (dark-blue points). In queenless colonies (light-blue points), the relationship is reversed and, as predicted by Hamilton's rule, workers are more altruistic in the species in which they are more related to each other. Modified, with permission, from Ref. [14].

greatly in excess of the one or two per year needed to head a swarm or replace a failing mother queen, but close to the figure expected on the basis of voluntary altruism alone (Box 1). The excess individuals are useless because they can neither work nor found colonies independently, and they are swiftly executed by the workers [23]. Similar evidence for overproduction of reproductives comes from some lower termites [17,24]. Here individuals retain the ability to moult into replacement reproductives and upon loss of the royal pair many do so, even though only one of each sex is needed and the excess individuals are killed [24] (Figure 2).

\section{Evasion of coercion}

If social insect workers are coerced into acting altruistically, strong selection for individuals to evade coercion is also expected. There is good evidence for such evasion (Figure 4). For example, in trigonine stingless bees, queens are normally reared in larger cells, but in several species females in worker cells evade an intended worker fate by developing as miniature queens [25]. These dwarf queens can successfully head colonies but appear to be under-represented. In one species, Schwarziana quadripunctata, $86 \%$ of the queens reared are dwarf queens but only $22 \%$ head colonies [26]. The lower success of dwarf queens relative to normal queens explains why in $S$. quadripunctata relatively few, $0.6 \%$, of the female larvae in worker cells become dwarf queens $[7,26]$. There is also evidence that workers actively try to evade egg policing. In anarchistic and parasitic Cape honeybees, workers can lay eggs that evade policing, possibly by chemically mimicking queen-laid eggs [27,28]. Workers of the Asian honeybees Apis florea and Apis cerana evade policing by a form of parasitism, laying eggs in unrelated queenless colonies in which worker policing has been switched off so that the colony can rear a last batch of males [29,30]. Bumblebee workers sometimes even go to the extreme measure of killing their mother queen to evade queen policing [31].

\section{Selection for coercion}

Coercion is clearly important in promoting altruism in insect societies. But why is it selected for in the first place? Inclusive fitness theory shows that coercion can have two chief benefits: (i) to increase total colony reproduction; or (ii) to increase the relatedness of coercers to the young queens and males reared [32].

The first benefit occurs in species in which egg-laying workers are aggressed, because this can force them to work harder and thereby increase colony reproduction $[13,19]$. Preventing excess queens from being reared boosts colony reproduction because it increases worker production [21].

The second benefit is important in both the selection for queen policing and worker policing. Queen policing has a relatedness benefit because a queen is twice as related to her own offspring as to her daughter workers' offspring (grandoffspring). Similarly, worker policing of worker-laid eggs can have a relatedness benefit when policing workers are more related to the queen's (or queens') sons than to those of other workers (Box 2). This occurs when the mother queen is mated to two or more males, or when the colony is headed by multiple related queens $[2,32,33]$. The extent to which empirical data support this prediction has proved controversial (Box 2). However, a recent analysis of over 100 species [18] shows that worker policing does occur more frequently, and that male production by workers is lower, in species in which the workers are more related to the queen's sons than to those of other workers (Box 2). Nevertheless, worker policing also occurs in some species with singlemated queens [34], which suggests that it can also have other benefits (Box 2). Although relatedness to queen's sons versus other workers' sons does explain a significant fraction of the observed variation among species in male parentage, much remains to be explained [34]. In particular, many species with single-mated queens have little or no worker reproduction [34]. In some of these species, such as the hornet Vespa crabro (18), there is strong evidence for worker policing, but in others, such as the lower attine ants [35], it is unclear whether egg policing occurs. 


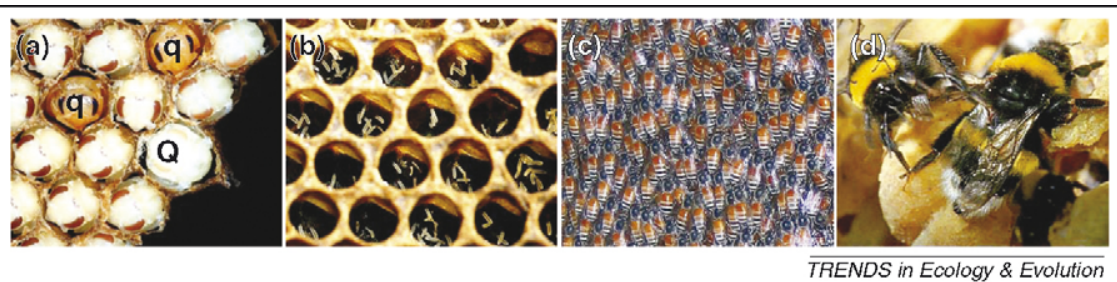

Figure 4. Evasion of coercion in insect societies. (a) Opened brood comb of the stingless bee Schwarziana quadripunctata showing two females who have evaded an intended worker fate by developing as dwarf queens (q) [26]; the large peripheral cell contains a normal-sized queen ( $Q$ ); (b) parasitic Cape bee workers, Apis mellifera capensis, lay eggs that are not policed in colonies of their host, Apis mellifera scutellata, resulting in the accumulation of multiple eggs per cell [28]; (c) workers of the dwarf honeybee Apis florea join and lay eggs in unrelated queenless colonies in which worker policing is switched off [29]; (d) to evade queen policing, workers of the bumblebee Bombus terrestris sometimes kill their mother queen [18,31]. Reproduced, with permission, from T. Wenseleers (a), F.L.W. Ratnieks (b), B. Oldroyd (c) and the BBC Natural History Unit (Life in the Undergrowth series) (d).

\section{Was coercion important in the evolution of eusociality?}

Coercion is important in promoting altruism in extant insect societies, but could it also have had a role in the origin of eusociality? In 1974, Richard Alexander proposed that parents might force their offspring to act as helpers [9]. Thirty years on, what is the evidence for such parental manipulation in the origin of insect eusociality? From a theoretical point of view, the idea is attractive because in both haplodiploids and diplodiploids individuals are, on average, as related to their full siblings (brothers and sisters) as they are to their own offspring (sons and daughters) [36]. As a result, individuals should not be selected to resist parental manipulation (or manipulation by their siblings), provided that they help to rear full siblings and that their labour is used as productively as when rearing their own offspring [36,37].

At an empirical level, primitively eusocial species have a range of coercive behaviours. For example, in the Asian paper wasp Polistes chinensis, the queen kills up to $70 \%$ of the eggs laid by workers [38]; in the allodapine bee Exoneura robusta, the queen can prevent workers that have mated from re-entering the nest [39]; in the ponerine ant Dinoponera quadriceps, workers that attempt to over-

\section{Box 2. Controversy: the selective basis of worker policing}

In 1984, Starr first raised the idea that workers in insect societies should be selected to inhibit each other from reproducing when they are more related to the queen's sons than to other workers' sons [33]. This occurs when the mother queen is mated to two or more males $[32,33]$ or when the colony is headed by several related queens [2]. Subsequently, the theory was formalized and extended using an explicit population genetic model by Ratnieks [32] in 1988. Support for the theory came a year later, with the discovery that workers kill or 'police' each others' eggs [6] in the honeybee, a species in which, as predicted, queens mate with multiple males [15].

Recently, the role of multiple mating and low relatedness in selecting for worker policing has been disputed, because worker policing also occurs in species in which queens usually mate only once $[18,34,69,70]$. In addition, an analysis of 50 species of ants, bees and wasps showed that relatedness apparently had no effect on male parentage [34]. However, a more extensive analysis showed that both policing and male parentage are significantly correlated with relatedness, as predicted [18,32] (Figure la,b). Nevertheless, a significant amount of the variation in male parentage remains unexplained by the relatedness of workers to males [34]. In addition, the fact that worker policing occurs in species with single-mated queens $[18,34]$ suggests that worker policing has other benefits, including the possibilities that workers kill worker-laid eggs as part of a strategy to cause a female-biased sexallocation ratio [69] or because workers aggress egg-laying workers to increase their work rates to improve colony productivity [32]. In addition, in some species, policing workers gain direct reproductive benefits because they lay eggs themselves $[38,71,72]$. Finally, Pirk et al. suggested that worker policing in the honeybee is aimed at removing unviable worker-laid eggs [73]. This idea, however, has since been disproven since dead queen-laid eggs are not policed in the honeybee [74], contrary to what is expected if egg policing is merely a form of hygienic behaviour aimed at removing dead individuals. In addition, worker-laid eggs are generally viable as queenless colonies of most species typically rear a large batch of workers' sons. (a)

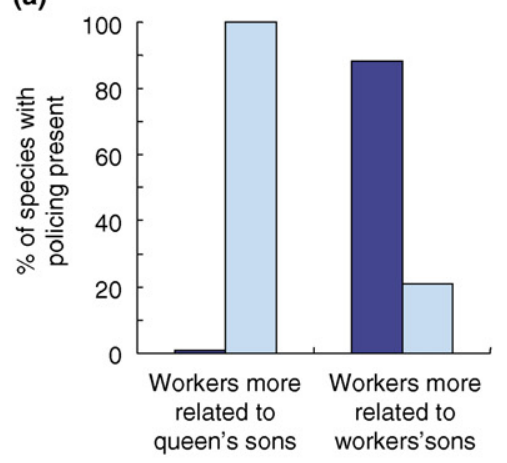

(b)

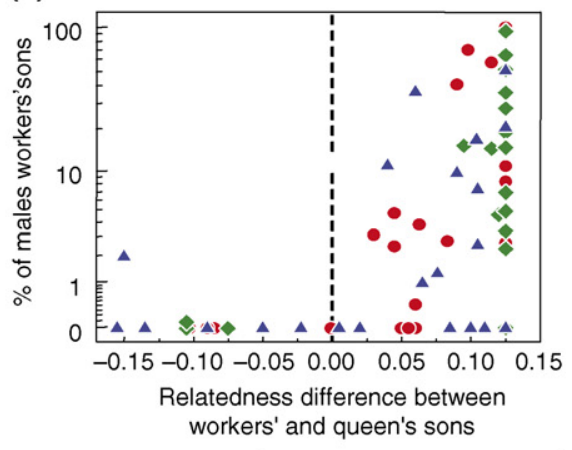

Figure I. Supporting evidence for the role of relatedness in the evolution of worker policing. (a) Across 48 species of ants, bees and wasps, worker policing (light-blue bars) occurs more frequently in species in which workers are more related to the queen's sons. For queen policing (dark-blue bars) the reverse is seen. (b) Across 90 species of ants (circles), bees (squares) and wasps (triangles), the mean percentage of adult males that are workers' sons is 100 times lower, $0.14 \%$, in species in which the workers are more related to the queen's sons (area to the left of the dashed line) than in species in which the workers are more related to sons of other workers, $14 \%$. Both conclusions also hold if phylogeny is controlled for. Based on data from Ref. [18]. 
throw the queen are prevented from doing so by being spread-eagled by other workers [40]. This punishment ends the challenge. Finally, in the sweat bee Lasioglossum zephyrum, the queen guides forager workers to particular cells to deposit their pollen, thereby increasing the work efficiency of the colony and decreasing opportunities for workers to lay eggs [11,41]. Similar behaviour has also been noted in several other primitively eusocial bees and wasps [42].

Nevertheless, the fact that coercion occurs in primitively eusocial species does not mean that it was important at the origin of eusociality. Eusociality in these groups is ancient (20 million years in Halictidae bees and 40 million years in Allodapini bees [43]), and the sophisticated coercive and organizational behaviours that are seen only make sense in a eusocial context and so presumably evolved after eusociality. Are there any behavioural or physiological mechanisms that could have evolved before eusociality that could promote daughter altruism?

One mechanism would be if the adults underfed some larvae, so that they forced some individuals into a handicapped loser role, for which indirect reproduction would be the more profitable life history alternative $[9,10]$. Although pre-imaginal caste determination in some primitively eusocial bees and wasps is sometimes cited as support for this theory [44], there is little evidence that females in these species are forced into helper roles because of inadequate feeding $[45,46]$. For example, in the paper wasp Polistes annularis, the variance in size among foundresses on spring nests is not significantly greater than that of all females from their natal nests [46]. Recently, it has also been suggested that in bivoltine (with two generations per year) species, reproductive diapause can provide a mechanistic basis for differences in reproductive physiology between incipient queens and workers [47]. However, although this is a preadaptation that might have been co-opted into eusociality, it is not specifically coercive. One coercive behaviour that has been seen in non-eusocial species is egg eating. For example, Field [48] reports a digger wasp female eating an egg laid by an intruder female.

Overall, however, there is little evidence that parental manipulation had a significant role in the origin of eusociality. In fact, given that both parents and siblings benefit from coercing offspring to help their parents $[36,37,49]$ and that offspring are indifferent to being coerced if they are rearing full siblings [36], we suggest that eusociality should be more common if it had originated as a result of coercion.

\section{Does enforced cooperation and altruism also occur in other social groups?}

Coercion and enforced cooperation are not restricted to insect societies but also occur in vertebrate [12,50] including human [51,52] societies and multispecies mutualisms [53-55] (Figure 1). In contrast to insect societies, however, in which coercion typically promotes inequality in a group composed of related individuals [5], in human society and in mutualisms, coercion often promotes fairness and reduces exploitation or cheating in groups with low or zero relatedness [51,54]. In other words, coercion is used to promote cooperation rather than altruism. Another difference is that, whereas coercion in insect societies usually has indirect inclusive-fitness benefits, in social vertebrates and mutualisms it usually provides direct benefits [53,54]. For example, in mutualisms, individuals can terminate interactions with uncooperative partners, thereby focusing interactions onto more cooperative partners $[53,54,56]$. Similarly, in social vertebrates, punishment can have direct benefits to the punishing individual, such as by inducing the victim to behave more cooperatively in the future [50]. In such cases, punishment and stable social behaviour can evolve even at zero relatedness.

In vertebrate societies, enforcement can take varied forms: in cooperatively breeding cichlid fish, subordinates that do not help are evicted and thereby prevented from inheriting the natal territory [57]; monkeys punish individuals who do not share food [58], police disruptive individuals in the group [59] and enforce fairness by not cooperating with others perceived as unfair [60]; naked mole rat queens shove pups to stimulate them to work [61]. A particularly ruthless example of enforcement is found in meerkats, in which the dominant female suppresses the reproduction of subordinates [62]. If a subordinate female becomes pregnant when the dominant female is also pregnant, the dominant female subjects the subordinate female to aggressive attacks and temporarily evicts her from the group. This behaviour usually leads to abortion of the subordinate's brood [62].

Enforcement can also explain cooperation between species [53,54]. For example, the cleaner fish Labroides dimidiatus eats ectoparasites on its client reef fish but could also cheat by eating client tissue or mucus. Clients use three different mechanisms to enforce cooperation: (i) they avoid cleaners that have been observed cheating (partner choice); (ii) they switch to other cleaners (partner switching); and (iii) they aggressively chase uncooperative cleaners (punishment) [63,64]. After such punishment, cleaner fish act more cooperatively and are less likely to feed on mucus [63,64]. Similar examples occur in the mutualisms between yucca plants and their yucca moth pollinators [53,54] and between legume plants and nitrogen-fixing bacteria, in which plants sanction bacteria that fail to fix nitrogen by cutting resources to root nodules containing such bacteria [55].

Finally, recent studies in experimental economics show that humans have a strong tendency to punish individuals who do not reciprocate or act fairly [51,52]. For example, in the ultimatum game a resource is divided between two individuals. The first player decides how to divide the resource. The second player can then choose whether to accept his share or to reject it, in which case both players receive nothing. The rational strategy is for the first to offer a mimimal share and for the second player to accept whatever is offered. However, first players often offer an equal share, and second players frequently reject less [51]. The apparently altruistic behaviour of the first player and the spiteful behaviour of the second player, if offered a small share, makes no sense in the context of a single interaction with an anonymous partner. However, it could be explained on the basis of the presence of 'relatedness' owing to nongenetic, cultural causes (cultural relatedness) caused by the inheritance of identical cultural variants 
from common cultural ancestors [65]. Alternatively, and more likely, the results suggest that, in humans, single interactions with anonymous partners are uncommon and have not shaped our general social responses [66].

Other games also show that humans are willing to expend resources to punish selfish individuals [51]. Here, the paradox is to explain why punishment occurs given that it is costly to punish selfish individuals [51,65]. The benefits probably come from the repeated nature of human interactions. Punishment can be costly in the short term but beneficial in the long term [52]. Overall it is clear, however, that in humans, punishment forms a powerful mechanism for promoting cooperation. In an experimental setting, the presence of punishment increased levels of cooperation [67]. In a comparative study of 15 small-scale societies, levels of cooperation were correlated with the degree to which uncooperative individuals were punished [68]. This finding parallels results from insect societies showing that more stringent policing promotes greater worker altruism (Figure 3 ).

\section{Conclusion}

Coercion is a major cause of altruism in insect societies. Without coercion, altruism would still occur and societies would still function because family levels of relatedness are sufficient to cause most individuals to act altruistically. However, such societies would be more similar to queenless honey bee colonies or colonies of Melipona bees and Polistes wasps, in which a large proportion of the individuals tries to reproduce by developing into queens or by laying eggs. Insect societies in which most individuals are altruists, such as honey bee colonies with a queen, generally appear to be the result of effective coercive mechanisms [14].

Because coercion itself depends on inclusive fitness considerations and is very much influenced by kinship, the importance of coercion in causing worker altruism does not mean that inclusive fitness explanations of altruism are wrong [4]. In fact, the main effect of coercion is to alter the costs and benefits of acting selfishly or altruistically [8]

\section{Box 3. Outstanding questions}

o What general factors determine who has power in a social group, whether this is power to the society to coerce individuals or for individuals to evade social coercion?

o Does coercion, by promoting more efficient societies, help these species in ecological, macro-evolutionary terms, such as in interspecies competition [75]?

o Is coercion important in the evolution of eusociality [9,36,37]?

o What proximate mechanisms are involved in social coercion? For example, how do workers discriminate between queen-laid and worker-laid eggs?

o What factors promote worker policing and worker sterility in insect societies, and how do these factors interact $[18,34]$ ?

o What genes underlie the altruistic and coercive behaviours seen in insect societies?

o To what extent are altruism and cooperation in vertebrate, including human, societies voluntary versus enforced?

o To what extent can theories and examples from studying altruism and cooperation in insect societies be applied to other social systems, and vice versa?

o Why are humans willing to punish free-riders even at an apparent cost to themselves $[51,52]$ ? and so is inherently part of inclusive fitness theory $[4,5]$. It does mean, however, that inclusive fitness explanations are more complex than often realized.

Many questions remain concerning the role of coercion in the evolution of altruism and cooperation (Box 3). For example, the relative importance of enforcement in promoting and maintaining cooperation in vertebrate including human societies largely remains to be determined $[51,52,57,61]$. However, it is clear that coercion is often important in promoting altruism in extant insect societies, and the realization of this brings a full understanding of worker altruism within our grasp.

\section{Acknowledgements}

We are grateful to A. Bourke, J. Field and L. Keller for their valuable comments. This study was supported by a postdoctoral fellowship and a grant from the Research Foundation Flanders (grant no. GNM-B5996KAN2006 1.5.018.07N) to T.W.

\section{References}

1 Oster, G.F. and Wilson, E.O. (1978) Caste and Ecology in the Social Insects, Princeton University Press

2 Bourke, A.F.G. and Franks, N.R. (1995) Social Evolution in Ants, Princeton University Press

3 Hamilton, W.D. (1963) The evolution of altruistic behaviour. Am. Nat. 97, 354-356

4 Hamilton, W.D. (1964) The genetical evolution of social behaviour. I \& II. J. Theor. Biol. 7, 1-52

5 Ratnieks, F.L.W. et al. (2006) Conflict resolution in insect societies. Annu. Rev. Entomol. 51, 581-608

6 Ratnieks, F.L.W. and Visscher, P.K. (1989) Worker policing in the honeybee. Nature 342, 796-797

7 Wenseleers, T. et al. (2004) When resistance is useless: policing and the evolution of reproductive acquiescence in insect societies. Am. Nat. 164, E154-E167

8 Lehmann, L. and Keller, L. (2006) The evolution of cooperation and altruism - a general framework and a classification of models. J. Evol. Biol. 19, 1365-1376

9 Alexander, R.D. (1974) The evolution of social behavior. Annu. Rev. Ecol. Syst. 5, 325-383

10 West-Eberhard, M.J. (1975) The evolution of social behavior by kin selection. Q. Rev. Biol. 50, 1-33

11 Michener, C.D. and Brothers, D.J. (1974) Were workers of eusocial Hymenoptera initially altruistic or oppressed? Proc. Natl Acad. Sci. USA 71, 671-674

12 Frank, S.A. (2003) Perspective: repression of competition and the evolution of cooperation. Evolution Int. J. Org. Evolution 57, 693-705

13 Wenseleers, T. et al. (2004) Worker reproduction and policing in insect societies: an ESS analysis. J. Evol. Biol. 17, 1035-1047

14 Wenseleers, T. and Ratnieks, F.L.W. (2006) Enforced altruism in insect societies. Nature 444,50

15 Strassmann, J.E. (2001) The rarity of multiple mating by females in the social Hymenoptera. Insectes Soc. 48, 1-13

16 Ratnieks, F.L.W. (1993) Egg-laying, egg-removal, and ovary development by workers in queenright honey-bee colonies. Behav. Ecol. Sociobiol. 32, 191-198

17 Wenseleers, T. et al. (2003) Caste fate conflict in swarm-founding social Hymenoptera: an inclusive fitness analysis. J. Evol. Biol. 16, $647-658$

18 Wenseleers, T. and Ratnieks, F.L.W. (2006) Comparative analysis of worker reproduction and policing in eusocial Hymenoptera supports relatedness theory. Am. Nat. 168, E163-E179

19 Liebig, J. et al. (1999) Worker policing limits the number of reproductives in a ponerine ant. Proc. R. Soc. Lond. B. Biol. Sci. $266,1865-1870$

20 Bourke, A.F.G. and Ratnieks, F.L.W. (1999) Kin conflict over caste determination in social Hymenoptera. Behav. Ecol. Sociobiol. 46, 287297

21 Ratnieks, F.L.W. (2001) Heirs and spares: Caste conflict and excess queen production in Melipona bees. Behav. Ecol. Sociobiol. 50, 467-473 
22 Wenseleers, T. and Ratnieks, F.L.W. (2004) Tragedy of the commons in Melipona bees. Proc. R. Soc. Lond. B. Biol. Sci. 271, S310-S312

23 Wenseleers, T. et al. (2004) Queen execution and caste conflict in the stingless bee Melipona beecheii. Ethology 110, 725-736

24 Myles, T.G. (1999) Review of secondary reproduction in termites (Insecta: Isoptera) with comments on its role in termite ecology and social evolution. Sociobiology 33, 1-91

25 Ribeiro, M.F. et al. (2006) Miniature queens in stingless bees: basic facts and evolutionary hypotheses. Apidologie (Celle) 37, 191-206

26 Wenseleers, T. et al. (2005) Working-class royalty: bees beat the caste system. Biol. Lett. 1, 125-128

27 Barron, A.B. et al. (2001) Worker reproduction in honey-bees (Apis) and the anarchic syndrome: a review. Behav. Ecol. Sociobiol. 50, 199-208

28 Martin, S.J. et al. (2002) Parasitic Cape honeybee workers, Apis mellifera capensis, evade policing. Nature 415, 163-165

29 Nanork, P. et al. (2005) Asian honeybees parasitize the future dead. Nature 437, 829

30 Nanork, P. et al. (2006) Social parasitism by workers in queenless and queenright Apis cerana colonies. Mol. Ecol. 16, 1107-1114

31 Bourke, A.F.G. (1994) Worker matricide in social bees and wasps. J. Theor. Biol. 167, 283-292

32 Ratnieks, F.L.W. (1988) Reproductive harmony via mutual policing by workers in eusocial Hymenoptera. Am. Nat. 132, 217-236

33 Starr, C.K. (1984) Sperm competition, kinship, and sociality: a review of modern theory. In Sperm Competition and the Evolution of Animal Mating Systems (Smith, R.L., ed.), pp. 427-464, Academic Press

34 Hammond, R.L. and Keller, L. (2004) Conflict over male parentage in social insects. PLoS Biol. 2, 1-11

35 Villesen, P. and Boomsma, J.J. (2003) Patterns of male parentage in the fungus-growing ants. Behav. Ecol. Sociobiol. 53, 246-253

36 Charnov, E.L. (1978) Evolution of eusocial behavior: offspring choice or parental parasitism? J. Theor. Biol. 75, 451-465

37 Stubblefield, J.W. and Charnov, E.L. (1986) Some conceptual issues in the origin of eusociality. Heredity 57, 181-187

38 Saigo, T. and Tsuchida, K. (2004) Queen and worker policing in monogynous and monandrous colonies of a primitively eusocial wasp. Proc. R. Soc. Lond. B. Biol. Sci. 271 (Suppl.), S509-S512

39 Bull, N.J. et al. (1998) Giving your daughters the edge: bequeathing reproductive dominance in a primitively social bee. Proc. R. Soc. Lond. B. Biol. Sci. 265, 1411-1415

40 Monnin, T. et al. (2002) Pretender punishment induced by chemical signalling in a queenless ant. Nature 419, 61-65

41 Breed, M.D. and Gamboa, G.J. (1977) Behavioral control of workers by queens in primitively eusocial bees. Science 195, 694-696

42 Jeanne, R.L. (2003) Social complexity in the Hymenoptera, with special attention to the wasps. In Genes, Behaviors and Evolution of Social Insects (Kikuchi, T. et al., eds), pp. 81-130, Hokkaido University Press

43 Schwarz, M.P. et al. (2007) Changing paradigms in insect social evolution: insights from Halictine and Allodapine bees. Annu. Rev. Entomol. 52, 127-150

44 O'Donnell, S. (1998) Reproductive caste determination in eusocial wasps (Hymenoptera: Vespidae). Annu. Rev. Entomol. 43, 323-346

45 Karsai, I. and Hunt, J.H. (2002) Food quantity affects traits of offspring in the paper wasp Polistes metricus (Hymenoptera: Vespidae). Environ. Entomol. 31, 99-106

46 Reeve, H.K. (1991) Polistes. In The Social Biology of Wasps (Ross, K.G. and Matthews, R.W., eds), pp. 99-148, Cornell University Press

47 Hunt, J.H. and Amdam, G.V. (2005) Bivoltinism as an antecedent to eusociality in the paper wasp genus Polistes. Science 308, 264-267

48 Field, J.P. (1992) Intraspecific parasitism as an alternative reproductive tactic in nest-building wasps and bees. Biol. Rev. 67, $79-126$

49 Linksvayer, T.A. and Wade, M.J. (2005) The evolutionary origin and elaboration of sociality in the aculeate Hymenoptera: Maternal effects, sib-social effects, and heterochrony. Q. Rev. Biol. 80, 317-336

50 Clutton-Brock, T.H. and Parker, G.A. (1995) Punishment in animal societies. Nature $373,209-216$

51 Gintis, H. et al., eds (2005) Moral Sentiments and Material Interests: The Foundations of Cooperation in Economic Life, The MIT Press

52 Sigmund, K. Punish or perish: enforcement and reciprocation in human collaboration. Trends Ecol. Evol. (in press)

53 Sachs, J.L. et al. (2004) The evolution of cooperation. Q. Rev. Biol. 79, $135-160$

54 Foster, K.R. and Wenseleers, T. (2006) A general model for the evolution of mutualisms. J. Evol. Biol. 19, 1283-1293

55 Kiers, E.T. et al. (2003) Host sanctions and the legume-rhizobium mutualism. Nature 425, 78-81

56 West, S.A. et al. (2002) Sanctions and mutualism stability: when should less beneficial mutualists be tolerated? J. Evol. Biol. 15, 830-837

57 Balshine-Earn, S. et al. (1998) Paying to stay or paying to breed? Field evidence for direct benefits of helping behavior in a cooperatively breeding fish. Behav. Ecol. 9, 432-438

58 Hauser, M.D. (1992) Costs of deception - Cheaters are punished in Rhesus monkeys (Macaca mulatta). Proc. Natl Acad. Sci. USA. 89, 12137-12139

59 Flack, J.C. et al. (2006) Policing stabilizes construction of social niches in primates. Nature $439,426-429$

60 Brosnan, S.F. and de Waal, F.B.M. (2003) Monkeys reject unequal pay. Nature 425, 297-299

61 Stankowich, T. and Sherman, P.W. (2002) Pup shoving by adult naked mole-rats. Ethology 108, 975-992

62 Young, A.J. et al. (2006) Stress and the suppression of subordinate reproduction in cooperatively breeding meerkats. Proc. Natl Acad. Sci. USA 103, 12005-12010

63 Bshary, R. and Grutter, A.S. (2005) Punishment and partner switching cause cooperative behaviour in a cleaning mutualism. Biol. Lett. 1, 396-399

64 Bshary, R. and Grutter, A.S. (2006) Image scoring and cooperation in a cleaner fish mutualism. Nature 441, 975-978

65 Lehmann, L. et al. (2007) Strong reciprocity or strong ferocity? A population genetic view of the evolution of altruistic punishment. Am. Nat. 170, 21-36

66 Hagen, E.H. and Hammerstein, P. (2006) Game theory and human evolution: a critique of some recent interpretations of experimental games. Theor. Popul. Biol. 69, 339-348

$67 \mathrm{Fehr}$, E. and Gächter, S. (2002) Altruistic punishment in humans. Nature 415, 137-140

68 Henrich, J. et al. (2006) Costly punishment across human societies. Science 312, 1767-1770

69 Foster, K.R. and Ratnieks, F.L.W. (2001) The effect of sex-allocation biasing on the evolution of worker policing in hymenopteran societies. Am. Nat. 158, 615-624

70 Nonacs, P. (2006) Nepotism and brood reliability in the suppression of worker reproduction in the eusocial Hymenoptera. Biol. Lett. 2, 577579

71 Wenseleers, T. et al. (2005) Queen and worker policing in the tree wasp Dolichovespula sylvestris. Behav. Ecol. Sociobiol. 58, 80-86

72 Stroeymeyt, N. et al. (2007) Selfish worker policing controls reproduction in a Temnothorax ant. Behav. Ecol. Sociobiol. 61, 1449-1457

73 Pirk, C.W.W. et al. (2004) Egg viability and worker policing in honey bees. Proc. Natl Acad. Sci. USA 101, 8649-8651

74 Beekman, M. and Oldroyd, B.P. (2005) Honey bee workers use cues other than egg viability for policing. Biol. Lett. 1, 129-132

75 Reeve, H.K. and Hölldobler, B. (2007) The emergence of a superorganism through intergroup competition. Proc. Natl. Acad. Sci. U. S. A. 104, 9736-9740 